\title{
Causes and Effects of Begging Style Involving Children as Guides in Dodoma Municipality, Tanzania: Liability in Basic Education Access
}

\author{
Abdallah Jacob Seni \\ Department of Educational Foundations and Continuing Education, University of Dodoma, Tanzania \\ E-mail: ajseni@gmail.com
}

Received: 16-11-2016

doi:10.7575/aiac.ijels.v.5n.1p.1
Accepted: 27-01-2017

Published: 31-01-2017

\begin{abstract}
This paper explores the causes and effects of a unique begging style involving children as guides in Dodoma Municipality, Tanzania. The rationale for Dodoma Municipality to be the study location is that the begging phenomenon using children as guides is rampant. The study sample involved 40 respondents, of whom 6 were young carers of visually impaired adult beggars, 6 visually impaired adult beggars, 6 young carers of visually impaired adult beggars' family members and 22 influential community members. Purposeful sampling technique was used to obtain these respondents. Data collection methods entailed interviews and observations. Artifacts were also used to portray issues under investigation more vividly. The data were analyzed using content analysis in which themes and sub-themes were determined by organization, reduction and interpretation of the information collected. The study discovered that lack of education, sympathy attraction, lack of proper orientation, laziness and poverty were the major causes for the existence of begging involving children as guides. The study revealed that minor causes include parents' negligence and alcoholism, Single Parenthood as well as drought and hunger. The begging style using children as guides resulted into notable limited basic education access among these vulnerable children hence a liability and not asset. The study recommends that young carers of visually impaired adult beggars should be enrolled to basic education and revitalize education for self-reliance.
\end{abstract}

Keywords: Basic Education Access, Visually Impaired Adult Beggars, and Young Carers

\section{Introduction}

Visually impaired adult beggars (VIABs) in Dodoma Municipality of Tanzania are guided by young children (mainly between the ages of five and thirteen). The VIABs who may be the parents, grandparents, distant relatives or even neighbours of these children use them in the begging process all the daylong either with or without payment (Seni, 2015, Seni, 2016). In the context of this paper, the young children who guide the VIABs are referred to as young carers of visually impaired adult beggars (YCVIABs) as they are young by their age (mainly 5 to 13) and take more substantial care to the VIABs apart from those of guiding in the begging process including but not limited to cooking for them, making shopping, washing and even intimate care such as toileting. These caring roles are not only beyond their age but are detrimental to their health and threatens their basic education access and participation. The focus of this paper is on the guidance role in the begging process and its effects on education of YCVIABs.

In traditional societies, where small group of people especially relatives live together and come to help one another, it was very uncommon to see begging. Begging became a common phenomenon with the gradual breaking of mutual helping system. The complication of support system, drought, hunger and poverty are other cited causes for street begging (Fikru, 2011; Namwata, Mgabo, and Dimoso, 2012). The phenomenon of street begging in Tanzania and Dodoma Municipality in particular emanates from urbanization and spearheaded by drought, famine and depressed economic activities. Drought and hunger have especially resulted into abject poverty among the original inhabitants of Dodoma Municipality (Namwata et al, 2012). The tough life amidst drought and hunger arguably tempt some community members to resort into survival strategies including street begging. Street begging in Dodoma municipality is unique as it involves visually impaired adult beggars (VIABs) accompanied by children as their guides. In this paper, the children who guide VIABs are referred to as Young Carers of Visually impaired adult beggars (YCVIABs).

YCVIABs are a group of street children below the age of eighteen (18) and constitute one of the categories of the Most Vulnerable Children (MVC) in Tanzania and in particular Dodoma Municipality. The guidance role may be detrimental to these vulnerable children including failure to access basic education and subsequently resort to begging as means of life during their adulthood.

A significant number of children worldwide are involved in some kind of care for members of their families, often parents. There were 175,000 young carers living in the United Kingdom (UK) alone (Evans and Becker, 2007). However, in developed countries, there are policies and programmes in favour of the care taker and the person cared for. In the United Kingdom for instance, a number of legislations are in place, including Carers Recognition and 
Services Act 1995, Carers and Disabled Children Act 2001, and Carers Equal Opportunities Act (Fives; Kennan; Canavan; Brady, and Cairns, 2010). In the USA, a number of people with disabilities are cared by community- based agencies (Angrosino, 1992). MVC, including YCVIABs in developing countries, have never attracted serious Policy attention. Tanzania is among the developing countries with young carers and about $4 \%$ of children aged between 7 and 14 years in the country were documented to be engaged in care giving (Robson, Ansell, Huber, Gould, and Van Blerk, 2006). Though there are various MVC related policies such as the Law of the Child Act (URT, 2009) and Child Development Policy (URT, 1996), MVC including YCVIABs, have not been reached and effectively mainstreamed (Correl \& Correl, 2010, Seni, 2016). Despite ratification of the Convention on the Rights of the Child of 1989 and the World Declaration on Education for All of 1990, the second EFA goal which set to achieve Universal Primary Education (UPE) have been missed by a wide margin, among the eligible children in Tanzania (UNESCO, 2014). This situation is likely to be worse for YCVIABs calling for a study to be undertaken.

\subsection{Research Purpose and Questions}

The primary concern of this study was to explore the causes of a unique begging style involving children as guides in Dodoma Municipality, Tanzania and how they affect access to basic education among YCVIABs. The study, thus, embarked on answering the following research questions:

i. What are the causes of existence of a unique begging style involving young children as guides in Dodoma Municipality?

ii. What are the effects of this begging style on the children's education?

This paper contributes to an already emerging literature on MVC, young carers, and beggars. The paper expects to enable the government, non-governmental organizations and related stakeholders to formulate policies and laws that may abolish beggary using children as guides. Consequently realization of widened basic education access among YCVIABs could be possible.

\section{Review of Related Literature}

\subsection{Theoretical Framework}

This study was framed within two theories namely childhood and social exclusion theories. The two theories were used to complement each other. They helped to illuminate issues under investigation and guided the study.

\subsubsection{Childhood Theory}

The founders of childhood theory are Johann Amos Comenius (1592-1670) and John Locke (1632-1704). The theory of childhood recognizes that 'childhood' is a socially constructed concept which varies according to historical and socio- cultural perception of the child, the socio-economic and political context within which children's lives are situated. The conflicting definition of childhood according to context also helps in explaining what it means to be a child (Bass, 2004; and James and Pront, 1997). The theoretical stances of the childhood theory include but not limited to the rights of the child for education and health services, protection against risks and vulnerabilities including not being exposed to street risks.

Skovdal (2009) also used the constructions of childhood as the starting point of his thesis and distinguishes between good or normal childhood as opposed to bad or abnormal childhood. Drawing from Boyden (1997) and Edwards (1996); Skovdal (2009) stipulated that the western understanding of childhood on the concept of "good childhood" has become globalized through policies, child rights debates, and international development. This study draws on this understanding to ascertain the extent to which YCVIABs were inclusive in the global trend regarding "good childhood" in the sense of availing to basic needs such as access to and full participation in basic education.

\subsubsection{Social Exclusion Theory}

"Exclusion" (les exclus) as a term, was first used in France, in 1960's as a form of social critique. Rene Lenoir in the Gaullist government in 1974 first spoke of the "excluded", referring to "various classes of people that were seen as "misfits", such as intellectually and physically disabled, suicidal persons, substance abusers, single parents, and various other marginal and asocial persons unprotected by social insurance" (Ryan, 2007).

The concept of exclusion spread to Europe and was adopted in European Council in 1984 to include the following: The poor shall be taken to mean persons, families, and groups of persons whose resources (material, cultural and social) are so limited as to exclude them from the minimum acceptable way of life in the member state, in which they live (Room 1990:40; Holland, 2008, in Ryan, 2007). Since that time, the term social exclusion has become the subject of many theoretical discussions especially during 1990's, when the nation states were trying to adopt democratic values by providing opportunities to each group in society. In order to include the marginalized in the development processes, the concept of social exclusion became handy. In the context of YCVIABs, these children are socially excluded, because they are denied the opportunity of accessing basic services including health, education, and leisure. They are also deprived of social respect and subjected to abuse. In short, YCVIABs who contribute in family income, are subjected to abuse and neglect within and outside the family, and cannot attend school because of the guiding burdens. 


\subsection{Empirical Literature}

While the negative impacts of begging using children as guides may not be disputed, with the exception of a few studies, which focused on other categories of beggars such as those who beg without the guidance of children (Namwata, et al, 2010, 2011, 2012 and 2014), and those on beggars with disability such as broken legs, cut arms, mentally ill, leprosy, and even those without any kind of disability, little has been studied on beggars guided by young children in the begging process.

Much of the literature on child begging focuses on independent child beggars (Abebe, 2008, Abebe, 2013; and Save the Children, 2011). Research on young carers also confined to children caring for parents with mental illness (Aldridge and Becker, 2003). A large body of literature further focuses to children who care HIV/AIDS patients.

Becker (2007) examined the extent of children's informal care giving, how young carers differ from other children; and how children's caring has been explained in both developed and developing countries. The study was conducted in the United Kingdom, Australia, the United States, and from sub-Saharan Africa by using the review methodology of the research, social policy and service developments for young carers in each country. The findings indicated that the number of young carers varied from country to country and kept on increasing year after year. It also found that there were differences between what young carers do and other children. Furthermore, unlike the developed nations, in developing nations the specific issue of young carers had not been identified as a concern for public or social policy, even though the image of the child as a carer was beginning to permeate into descriptions of children affected by HIV/AIDS.

Evans and Becker (2007) explored the similarities and differences in the experiences, needs and resilience of children who care for parents or relatives with HIV/AIDS in Tanzania and the United Kingdom (UK). The child-focused methodology and participatory methods were employed to obtain in-depth insight into children's experiences. A life story book with sentence completion exercise was also used. Evans and Becker found that children performed a range of caring tasks in families affected by HIV/AIDS in the UK and Tanzania. The household chores included cooking, cleaning, washing dishes, laundry, shopping; (in Tanzania only) fetching water, tending livestock, cultivating crops and vegetables.

Although the household chores performed by children were broadly similar in the two countries, children's care work differs considerably in the intensity and time taken to perform household chores due to disparities in living standards between low and high income countries. In Tanzania, children's care work took longer and was more physically demanding than in the UK. Many children said that they liked caring for their parents or relatives because they felt that they were helping to make life easier for their parents or relatives. Some children in the UK thought that their parent's illness and caring responsibilities had helped them to become 'stronger' emotionally. However, several children in both countries expressed their worry and anxiety about the life-limiting nature of their parent's illness. Many children were afraid about what would happen when their mother died.

Skovdal (2009) mainly focused on the nature of caring roles and responsibilities, psychological needs of young carers, coping strategies among young carers to deal with their challenging social circumstances, and most feasible ways of providing psychological support to young carers in Africa. The study by Skovdal (2009) used the method of participatory action research to study the problems of young carers of HIV/AIDS patients in Western Kenya and found that many children view caring as a challenge and opportunity for personal growth and a socially valued service rather than a hindrance or obstacle in their lives. On the negative side, the study points out that the long-term impacts of their disrupted school attendance were the greatest concern for many children. While it seemed sound for children to consider caring roles positively, the study by Skovdal (2009) did not put into account that there were other categories of caring roles that might not be socially valued such as guiding beggars.

Through focus group discussion and interviews with beggars, Katsande (2012) mainly examined what blind begging is and why it exists. Katsande (2012) found that begging by the blind was a professional response to a perceived market need and the blind beggars has the physical infrastructure to successfully exploit this niche market and thus make a sustainable livelihood. Though the study by Katsande further found that blind beggars in Zimbabwe operate in different manner including begging independently or being escorted by other people (old, young and even children), little focus is given to the children guiding the visually impaired beggars and the underlying implications on this phenomenon to children's education.

A study by Sayibu (2013) used a qualitative approach in which in-depth interview and observation were the two main methods employed for gathering the primary data while documentary reviews taped secondary data. The study was set to explore the phenomenon of begging with a particular focus on the child-disabled adult partnership for street begging in Tamale, Ghana. It focused to understand how this practice works in Tamale and its implication on the rights and welfare of the child. Sayibu (2013) found that almost all the disabled particularly the blind employ the services of children to serve as their aides or guides. Though the study by Sayibu (2013) reveals that children involved in the begging partnership face major constraints in achieving personal wellbeing in terms of their aspirations for education and other economic opportunities, less details are given on educational implications emanating from the "begging partnership". 
There is paucity of information on the causes and effects of begging style using children as guides adopted by VIABs locally and internationally. Lack of knowledge in this area is a handicap to policy and practice issues to overcome the problem facing YCVIABs in Tanzania. As that fundamental, a need emerged to bridge this knowledge gap.

\section{Methodology}

Qualitative research approach was used due to the intention of the researcher to obtain in-depth data, regarding the causes of begging style involving children as guides and the underlying effects on basic education access (Cohen, Manion, and Morrison, 2000). The study used intrinsic case study which Ary, Jacobs and Sorensen (2010) say is conducted to understand a particular case that may be unusual, unique, or different in some way. The study also used phenomelogical design as it intended to capture the meanings that YCVIABs, VIABs, Young Carers of Visually Impaired Adult Beggars' Family Members (YCVIABFMs) and influential community members attached to the causes of a unique begging style using children as guides.

The study location was Dodoma municipality of Tanzania since it has more VIABs (Namwata et al, 2010). There was also a rapidly increasing number of MVC generally and YCVIABs in particular. Estimated figures of MVC by 2012 were 7,635, while that of street children including YCVIABs were around 170 (Seni, 2015). The total sample for this study was 40 respondents including 6 YCVIAs, 6 VIABs, 6 YCVIABFMs, (22 influential community members) which include 4 Ward Executive Officers (WEOs), 3 ward education coordinators (WECs), 3 head teachers (HTs), and 4 ward councilors (WCs). Other respondents were 3 religious leaders (RLs), 3 Non- Governmental Organization (NGO) Coordinators, 1 social welfare officer (SWO) and 1 Community Development Officer (CDO).

Purposive sampling of YCVIABs and VIABs was used as they were key targets of this study and so their views were significant. Snowballing, incidental or accidental techniques were employed to YCVIABs and VIABs in order to overcome their moving nature (Namwata et al, 2010). The accessed YCVIABs and VIABs were asked to reveal the whereabouts of others. Public places where YCVIABs were generally found including Nyerere Square, hotels, restaurants, bars, near automatic teller machines, churches, mosques, markets, the famous One Way Road and bus stands were further selected to overcome their moving nature. Purposive sampling was also employed to sample YCVIABFMs, (Influential community members) WCs, RLs, NGO coordinators, SWO and CDO as they were considered to be information rich and can represent a huge section of the entire community members.

Data were collected through interviews and direct-non participant observations. Artifacts were used to depict issues under study vividly (Seni, 2016). The data analysis process was guided by Pellegrin's (1998) two principles, namely homogeneity and mutual exclusiveness in which both deductive and inductive processes were used to determine the main themes and sub- themes respectively (Ezzy, 2002). All the data sets from interviews and observations were analyzed following procedures recommended by Miles and Hubberman (1994) that is data organization, reduction and interpretation. The audiotapes that contained interview data were carefully listened to and transcribed. Critical listening and reading of the repeating ideas were done to determine themes. The observational data and artifacts were analyzed by reading carefully notes on the causes for the existence of the unique begging style involving children as guides. Then, the noted observed causes were transcribed with particular attention to the emerging educational effects.

The accuracy, truthfulness, credibility of the findings and the degree of consistency of research instruments were taken care of through a pilot study as argued by (Ary et al, 2010, Drever and Munn, 1990). The pilot study was conducted in Makole, a ward within the study location. The researcher used one research assistant and looked for consistency of the responses from the research participants. Triangulation of interviews and observation data was employed to ensure more trust (Miles and Huberman, 1994; Patton, 2002). Through thick description as argued by (Ary et al, 2010 and Lincoln and Guba 1985), the study used several quotations from research participants to provide more insights on the part of the reader regarding the meaning of data and establish trustworthiness. Back translation was also used in which interview guides which were initially in English were translated into Kiswahili (the national language) to ease communication with participants. The researcher handled the issue of ethical considerations and human subject protection more keenly. As recommended by Cohen et al. (2000), a formal research clearance from the University of Dodoma authority was obtained. Explanations regarding the objectives of the study to the research participants were given to solicit their consent (Cohen et al, 2005). Consent from VIABs who were literate was written in Braille dots with the aid of an expert and YCVIABs' consent was thought via the VIABs. As argued by Denzin (2000), all personal data were made public behind the shield of anonymity for confidentiality and to protect respondents from harm that may arise due to their participation in this study. Protection of human subject was considered critical in this study as it deals with a sensitive issue. Thus, though the power of photographs in explaining the phenomenon at hand more vividly is acknowledged (Fatterman, 1998 and Seni, 2013), yet the researcher decided to use artifact (drawn picture) instead of photograph so as to avoid breach of the right for anonymity and non-exposure of information that may humiliate the participants and attack their personality (Denzin, 2000; Frankfort- Nachmias and Nachmias, 1992). Street begging is one of the shameful and humiliative practices which require the researcher to move beyond the reliance of consent alone and masking of photographs. Creativity in terms of use of artifacts was important since lack of it would have culminated into attacking the personality of respondents and cause harm. Artifacts are becoming common in sensitive research such as those on HIV/AIDS (Evans and Becker, 2007 and Skovdal, 2009). 


\section{Findings and Discussion}

\subsection{Causes of Unique Begging Style Involving Children as Guides}

The causes of unique begging style involving children as guides were pointed based on the perspective of the categories of respondents namely influential community members and immediate victims of the phenomenon.

\subsubsection{Causes in the Perspective of Influential Community Members}

Findings indicate that, some factors were frequently pointed out as being responsible for the existence of the begging phenomenon involving children as guides and so regarded as the main causes. The findings revealed lack of education, sympathy attraction, lack of proper orientation, laziness and poverty as the major causes for the existence of begging involving YCVIABs as guides.

Lack of education to the part of the VIABs, and YCVIABFMs was nominated as one of the factors leading to the existence of the unique begging style using children as guides. In this regard, the CDO and NGO coordinator respectively had the following to say:

Lack of Education contributes to the existence of this plight, since the adult beggars cannot value to educate the YCVIAB while he or she did not go to school too (CDO).

The challenge that we can directly pose to the relatives of the VIABs, is their failure to understand right from the beginning that people with visual impairment were supposed to be sent to school during their childhood. The community and relatives around the VIAB need to be educated on the importance of educating people with impairment and the effects of using children as guides in the begging process (NGO Coordinator 1).

Regarding pretence and sympathy attraction, the findings revealed that VIABs use children as guides in the begging activity by thinking that it could attract more sympathy than going to beg on their own or using adults as their guides. In this regard, one of the HT interviewed had this to say:

These people are not "blinds," they just close their eyes and open them when they go back to their homes. They use young children in the begging process so that people may feel sorry for them and give them something. Most of the people would not wish to assist them as in so doing this undesirable culture will persist. However, the presence of a child attracts much sympathy (HT 1).

When asked a probing question about the fact that these beggars are disabled and so using a guide was inevitable, the HT and NGO coordinator respectively had this to add:

Using children as guides in the begging process is used as a strategy to attract more sympathy from people. They should rather use their partners (husbands or wives) or any other adult person having no schooling responsibility (HT 1).

They use children as targets for attracting sympathy. One feels sorry to a child, especially when seeing him or her going without eating, but I totally disagree with the use of children in guiding adults. The continued use of children as guides in the begging process is deep rooted in a negative attitude of viewing people with impairments as unproductive members in the society (NGO Coordinator 1).

A picture drawn by one of the participants, an influential community member, in artifact 1 illustrates this point more vividly. In artifact 1 , the YCVIAB seems to be tired and hungry and the passerby is giving a coin to the VIAB as a result of sympathy to the child. Findings have further revealed lack of proper orientation regarding life and a sense of responsibility among members of a family as the causality of the phenomenon. In this regard, one of the interviewed HTs and RLs respectively intimated:

The problem is not only poverty but an attitude issue, that is, if one goes to beg can gain something. The community is not fully oriented to the potentiality of their surrounding environment so that they can utilize it rather than begging by using children. You may for example hear that someone has cows in the village despite his or her disability, but surprisingly he or she comes in the town and beg using a child as guide (HT 2). 
In Dodoma, this problem is more pronounced due to lack of proper orientation among family members. Even Holy books require us to raise children in a good way and show them a proper way of leading their life. By letting YCVIABs guide VIABs is like telling them that begging is a desirable thing and they should also be beggars during their adulthood (RL 1).

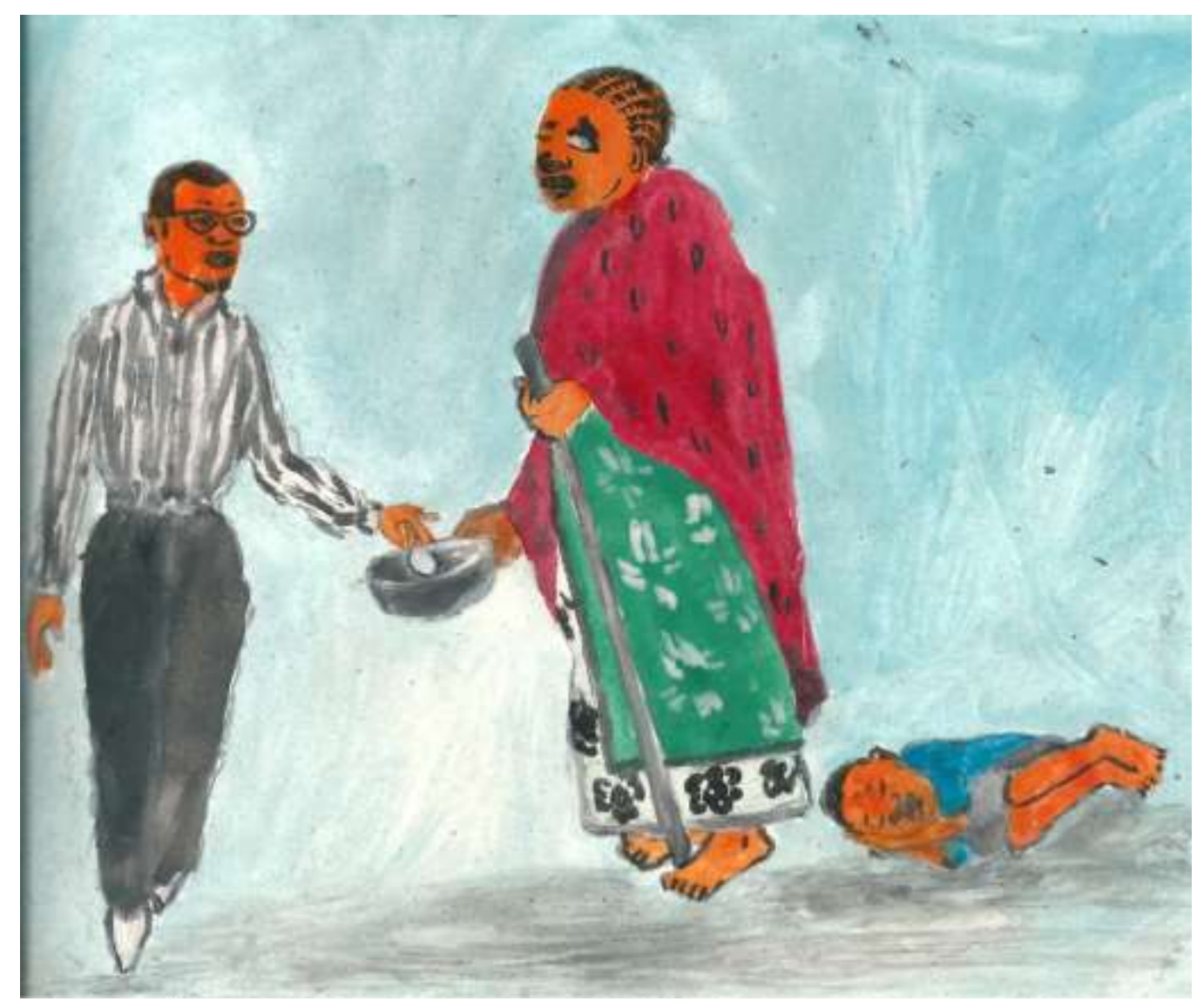

Artifact 1: A YCVIAB Sleeping on the Ground as a Passerby Giving a Coin to a VIAB (Source: Field Data, 2014)

Laziness was widely revealed as one of the causes of a unique begging style involving children as guides and so the plight that the YCVIABs faced. One of the interviewed CDO and RL respectively had the following to assert:

Laziness drives them to begging. Though Dodoma is a semi arid area but those who work hard can yield something. More badly, they are all not visually impaired but some pretend (CDO).

The inhabitants of Dodoma municipality are less hard working as compared to say people from Kondoa district, who could cultivate a large farm. We should also note that giving something to beggars is good but in a way, it is like encouraging the persistence of the beggary phenomenon (RL 3).

The contribution of poverty towards the existence of phenomenon in Dodoma municipality was clearly articulated by the respondents in this study. The participant SWO had the following to articulate:

Income Poverty causes people to beg. Remember not all people in Dodoma are begging but the poor are the ones engaged in this unique begging. The two, lack of education and poverty are linked together (SWO).

The CDO revealed that there were multifaceted perceptions regarding the causes of begging style using children as guides. Some respondents viewed poverty as a cause for the unique begging style involving children as guides and not a cause at the same time. The subsequent statements testify this: 
Poverty has a great contribution as children cannot go to school while there is nothing to eat, but others come from well off families and if you can make a follow up, you can find that they own a lot of cows in the villages where they come from (CDO).

Poverty may be both a cause or not; others are involved in beggary not due to poverty. Some involve in begging as a way of getting cheap earning and not working. It is just a habit and more of a culture than poverty $(\mathrm{CDO})$.

The pointed out minor factors include parents' negligence and alcoholism, Single Parenthood as well as drought and hunger. The subsequent voices from the participant RLs validate this respectively:

Negligence of fathers and much alcoholism contribute to the existence of begging phenomenon. Some fathers spend much of their time taking local brews resulting to the existence of orphans as their mother fail to sustain them. They leave the child to a grandparent who might be a visually impaired adult and poor. All of these lead the child to a tragic life of guiding the grandparent in the process of begging rather than going to school (RL 1).

Single parent families where children were born out of marriage and raised by mothers only lead children into the phenomenon of guiding VIABs in their begging activity. Neglectful persons may also impregnate women and leave the care of the children to them (RL 2).

There is drought in Dodoma and since the inhabitants are less hard working, the harvest they get cannot sustain their families throughout the year. The condition in Dodoma supports pastoralism but not every inhabitant has cows. The rain season lasts from November up to April thus the busiest months in the region is of five months, the rest of the months inhabitants have no economic activities to do and so resort into begging using children (RL 3).

\subsubsection{Causes in the Perspective of Immediate Victims (YCVIABs, VIABs and YCVIABFMs)}

Responding to the interview question that inquired them to explain on what should be done to them as a remedy to their plight, majority of the participant YCVIABs mentioned food as the first item that could be helpful to them. Nominating food as the first item implicitly suggested that it was the most critical factor leading them into the guiding role in the begging process. The subsequent voices of respondents illustrate this point:

Let them (community members and the government officials) give us a sack of flour, rice, cooking oil so that I can have food and go to school (YCVIAB 1).

Lack of food drives me to guide my father in begging. My father and mother are poor and they all do not see so we rely much on begging to earn our living. I guide my father in the begging process since it is the only way through which we earn our daily meals since the assistance we get from our neighbors and relatives are not sufficient to sustain our daily life (YCVIAB 2).

While the responses from one of the participant YCVIABs also implied poverty, such as not being able to afford daily life; another YCVIAB viewed visual impairment of her parents as a cause of begging involving them (YCVIABs) as guides, the subsequent voice evidence the view:

Both my father and mother are visually impaired as that being the case, we cannot live without begging. The money we get helps us to get our daily requirements (YCVIAB 3).

More than half of the participants VIABs alluded to their disability (visual impairment) as the leading cause for the existence of begging style involving children as guides. In the words of one of the interviewed VIAB, the following statement was recorded:

I also do not like to go around begging but due to my condition (visual impairment) I have to come to the town and beg. My child (a YCVIAB) does not attend to school as she has to bring me here and we all 
earn our living through begging. So she sometimes goes to school when we have saved a little money to sustain us (VIAB 1).

Likewise, one of the participant VIAB nominated poverty as one of the causes drifting them into beggary life involving children as guides. In this regard, one of the participants VIAB had the following to say:

In addition, to my condition (visual impairment) poverty within our family makes me resort into beggary life involving a child (YCVIAB) as we can earn some money to buy food for all of us (VIAB 2).

It was found out that almost all YCVIABFMs alluded to poverty and lack of food as the leading cause for the existence of begging style involving children as guides. While only one of the participant YCVIABFMs nominated visual impairment. In the words of the interviewed YCVIABFMs, the following statements were recorded:

The main cause for begging using children is the widespread poverty among our families. As relatives, we are also poor and cannot thus meet the requirements of our families and those of our disabled relatives. The solution is to let them go to town with their children and beg from good Samaritans (YCVIABFM 1).

The reason for begging using a child for our relative is his visual impairment condition which inhibits him from doing a productive work sufficient to earn his living (YCVIABFM 2).

Based on the findings, it could be argued and maintained that the main causes of begging phenomenon involving children as guides were poverty, lack of education, sympathy attraction, lack of proper orientation and laziness. Minor causes were parents' negligence and alcoholism, single parenthood as well as drought and hunger. In due regards, poverty, visual impairment, and lack of food were central causes, as they were nominated by almost all categories of the research participants including the immediate victims of the phenomenon namely YCVIABs and VIABs.

The community members implicitly exhibited a failure to acknowledge disability in particular, visual impairment as being a critical cause of begging phenomenon using children as guides. Failure to let their children go to school and failure of the relatives to take charge such as reporting the matter to the government officials reflects a degradation of an effective functioning of the family as a core for the society's progress, continuity and as an agent of child protection. The failure of families to address street children issues is also confirmed by Boaten (2006), who reports that the family in Ghanaian society used to be a place for protection and a comfort zone but the same was fading away.

Lack of education was considered to be the major cause in the perspective of influential community members but was not the case for the immediate victims of the phenomenon namely YCVIABs, VIABs, and YCVIABFMs. These findings, thus, imply a relatively high awareness among the influential community members, on the pivotal role of education that people had received in pulling them out of vulnerability, and the education that people had missed in pressing them in the disadvantaged position. Furthermore, the findings imply that the immediate target participants namely YCVIABs, VIABs, and YCVIABFMs, had a relatively low awareness regarding the strengths of having education as a way of capacitating them to live an independent life.

The findings that poverty has been cited by almost all categories of participants as one of the causes of the existence of begging involving children fails to consider the fact that, there are other regions in Tanzania which are so economically poor and their people are also economically incapacitated, but have never resorted into beggary phenomenon to a more pronounced extent and worse more, involving children who were supposed to be at school. However, the relationship between the widespread poverty and resorting to begging cannot be underestimated and is in record of various studies in the world.

In Ghana, poverty is one of the recurring themes regarding the causes which throw children in the streets (Boaten, 2006). In Kenya, poverty is one of the key factors associated with the problem of street children (Suda, 1997). Likewise, in South African street children are also caused by a widespread poverty among people (Malindi and Machenjedze, 2012 \& Ward and Seager, 2010). Another study conducted by Demartoto (2012) on street children in Surakarta City of Central Java Province of Indonesia, also refers to poverty as being one of the causes leading children into the street.

The link of laziness and the existence of the unique begging style involving children as guides of the VIABs, and so to the plight they (YCVIABs and VIABs) faced, could suggest the need for an overemphasize of the work spirit among the indigenous people in the study location. An access to Basic education in which education for Self-reliance (ESR) is revitalized could serve this purpose. 
The impact of alcoholism and negligence could suggest a lack of desire among some members to utilize the scarce resources available in the study location, for the betterment of children as though they mostly took local brews which were relatively cheaper, but that little money could have been committed for children's welfare including sending them to school. In Kenya, the increasing number of children, who are sent to work on the streets among other possible causes, is due to parents' desertion, parents who abuse alcohol and those who are neglectful (Suda, 1997, \& Acker, Oostrom, Rath, and Kemp, 1999). Alcoholism has also been documented as a cause leading children into the streets in Russia by Balachova, Bonner, and Levy (2009).

While few respondents from the influential community members' category pointed out categorically drought and hunger, as being one of the causes of the existence of the unique begging style involving children as guides, it was also evident in the study's general findings through observations that a relatively few YCVIABs and the VIABs were observed in the streets begging during the harvest season suggesting the significance role of drought and hunger to the pronouncement of this phenomenon. These findings are in akin with those by Skovdal (2009) who found that, drought and climatic conditions greatly increased the vulnerability of young carers of HIV/AIDS patients in Kenya.

\subsection{The Underlying Educational Effects YCVIABs Face}

The effects emanating from the unique begging style involving YCVIABs pose adverse educational problems to these vulnerable children. The guidance role consume a lot of time which could be used by these children attending to school. Majority of the YCVIABs have never got a chance to access basic education. Those who did were truants or have dropped from school completely. Data emerging from interviews with YCVIABs, VIABs, HTs and documentary reviews mainly school pupils' attendance registers validate this. The HT revealing the effects YCVIABs face asserted:

These children are not enrolled to primary education. They innocently spend a lot of their time guiding beggars. The few who are enrolled have poor school attendance as you will see in our records (HT 4).

One of the interviewed YCVIAB had the following to say:

I used to guide my father daily as it is the only way we can earn our daily meal. Nowadays my young sister helps me and so can sometimes go to school. I prefer going to school like other children but the condition (visual impairment) of my father forces me to miss that opportunity (YCVIAB 4).

On the same vein, a VIAB interviewed intimated that they wished to send the child to school but visual impairment inhibited them to do so. The following statements testify this:

The child (YCVIAB) used to go to school but as you can see my condition (visual impairment). I cannot sustain life without begging on the street. The money we earn is used to buy food for the whole family, so if I let her go to school where will she eat? (VIAB 3).

Data emerging from documentary reviews, in particular pupils' school attendance registers indicate that in average YCVIABs who were in school, attended only once a week. This arguably denies these children with time to study and their overall school development is jeopardized. The problem of irregular school attendance is also articulated in a study by (Anangisye, 2011). Evans and Becker (2007) also found that sometimes young carers of HIV/AIDS patients missed school due to their caring responsibilities, for periods of a few days up to several months when their parent was seriously ill. While these findings are similar, it can be argued that the findings that most of YCVIABs did not had chance to access basic education completely suggest how the effects entailed in the care roles vary in intensity. Guiding a VIAB is a daily undertaking and deprives these children of their basic education right as enshrined in the second EFA goal set to achieve Universal Primary Education (UPE) by 2015 (UNESCO, 2014).

The findings that the effects of the unique begging style involving YCVIABs pose adverse educational problems to these vulnerable children and that the guidance role consume a lot of time which could be used by these children attending to school contradicts with the childhood theoretical stance on the rights of the child for education.

Based on the findings and the theoretical underpinnings entailed in the social exclusion theory, it could be argued that YCVIABs represent one of the most critical cases of social exclusion in Tanzania because they experience harsh conditions of guiding VIABs all the daylong and at times receive disappointing response from the people they beg. YCVIABs are also sidelined in the achievements recorded by national and international commitments of widening basic education access for every child. Article four of the Tanzania law of the Child Act of 2009 states that, the government of Tanzania has a responsibility to take all available means to make sure that, children's rights are respected, protected, 
and fulfilled. The plight facing YCVIABs reflect the extent to which current MVC-related policies and laws for children have remained on paper work and missing in terms of practice.

The Development Vision 2025 intended to achieve high quality livelihood to all social groups, such as the boys and girls, youth and old, and able-bodied and disabled (URT, 2000). Realization of this vision stance has not been a reality to the part of VIABs, as part and parcel of the old and disabled and to YCVIABs as part and parcel of boys and girls. Although the Tanzanian country report on the Millennium Development Goals (MDG) of 2010, indicates that, the second MDG of achieving UPE has been realized as the Net Enrollment Ratio (NER) in primary education was $95.4 \%$ by 2010 (URT, 2011), yet on the basis of the findings in this study, in which some YCVIABs were out of school and those in school not fully participating, it could be argued that YCVIABs have been sidelined by this achievement.

The YCVIABs out of school further reinforce what Rubagumya (1991:76) found that the education system of Tanzania still functioned as a reproductive mechanism for small elite, rather than as an instrument towards egalitarianism. It also confirms that the children of more affluent parents in Tanzania are more likely to enter school and to progress than children of less affluent parents (Samoff, 1987:355).

\section{Conclusion and Recommendations}

The study concludes that the causes for the existence of the begging phenomenon involving children as guides varied depending on the perspectives of different stakeholders. In due regards, how the stakeholders viewed the causes for begging style using children as guides influenced their perception of the phenomenon and its unfolding plights. Majority of influential community members gave reasons which critically see the phenomenon as a result of the victims (YCVIABs and VIABs) consequently their negative perception which impaired their quest to support these vulnerable children and adults. This paper further concludes that the causes nominated and their resulting effects are liability and not asset to basic education access among YCVIABs.

As laziness was linked to the existence of the unique begging style involving children as guides, this paper recommends that YCVIABs should be enrolled to and participate fully in basic education in which Education for Self-reliance (ESR) also need to be revitalized so as to inculcate work spirit or love for work among these children. This will break the vicious cycle of poverty, dependence and street begging. Since this study revealed that there were instances in which the guiding roles were commercialized, a study on the possibilities for formalization of the guiding roles of VIABs as a strategy to pull adults in the guiding role and let children go to school may be considered.

From the study findings, it is apparently that there is a need for re-orientation regarding the strengths that the community possesses in terms of resources such as cows and elder relatives who could support the VIABs, through finding a relevant work for them to do and abandon such a humiliating phenomenon of begging. The community members should be enlightened and reminded that some of the people with visual impairment had elsewhere in the country and outside the country, gone to school and secured different positions of service in the community than those who were not impaired. To date some people with visual impairment from other areas serve as teachers in different levels of education, some are lecturers, members of parliaments and others have different talents such as beating drums, playing guitars and so forth.

\section{Acknowledgement}

The author would like to express innermost thanks to his $\mathrm{PhD}$ supervisors Prof. Elinami Veraeli Swai and Dr. Lyabwene Mtahabwa for their tireless guidance. Sincere thanks to the management of the University of Dodoma for the sponsorship of the PhD studies through Higher Education Students' Loans Board (HESLB) since part of the data collected during the studies were used in composing this paper.

\section{References}

Abebe, T. (2008). Earning a living on the margins: begging, street work and the socio-spatial experience of children in Addis Ababa. Geografiska Annaler: Series B, Human Geography, 90(3), 271-284.

Abebe, T. (2013). Interdependent rights and agency: the role of children in collective livelihood strategies in rural Ethiopia, in K. Hanson and O. Nieu-wenhuys (eds) Reconceptualizing Children's Rights in International Development: Living Rights, Social Justice, Translations, (pp.71-92). New York: Cambridge University Press.

Acker, J.V, Oostrom, B, Rath, B., \& Kemp, R. (1999). Street Children in Nairobi: Hakuna Matata? University of Nijmegen, the Netherlands: John Wiley \& Sons, Inc.

Aldridge, J., \& Becker, S. (2003). Children Caring for Parents with Mental Illness: Perspectives of Young Carers, Parents and Professionals. Bristol: The Policy Press.

Anangisye, W. A. L. (2011). Bottlenecks in the access to primary education in Tanzania: The struggles of vulnerable school children in Makete District. KEDI Journal of Educational Policy, 8(2, 323-344.

Angrosino, M. V., \& Zagnoli, L.J. (1992). Gender Constructs and Social Identity: Implications for Community- Based Care of Retarded Adults. In T. Whitehead \& Reid (Eds.) Gender Constructs and Social Issues (pp. 40-69). Urbana: University of Illinois Press. 
Ary, D; Jacobs, L.C., \& Sorensen, C. (2010). Introduction to Research in Education; Eighth Edition. Belmont: Wadsworth.

Balachova T. N, Bonner B. L., \& Levy, S. (2009). Street Children in Russia: Steps to Prevention. Miami: Blackwell Publishing Ltd and the International Journal of Social Welfare.

Bass, L. E. (2004). Child Labour in Sub-Saharan Africa. London: Lynne Rienner, Boulder.

Becker, S. (2007). Global Perspectives on Children's Unpaid Care Giving in The Family: Research and policy on 'young carers' in the UK, Australia, the USA and Sub-Saharan Africa', Global Social Policy, Vol. 7, no. 1, pp. 23-50.

Boaten, A.B. (2006). An Examination on the Phenomenon of Street Children in Selected Communities in Accra (Ghana), A Dissertation Presented to the Faculty of the College of Education of Ohio University in Partial Fulfillment of the Requirements for the Degree Doctor of Philosophy. Ohio: Ohio University Press.

Cohen, L, Manion, L., \& Morrison, K. (2000). Research Methods in Education. London: Routledge Falmer.

Cohen, L, Manion, L., \& Morrison, K. (2005). Research Methods in Education (5th Edition). London: Taylor and Francis.

Correl, L., \& Correl, T. (2010). The Tanzanian National Costed Plan of Action for Most Vulnerable Children: A Human Capacity Needs Assessment: Dar es Salaam: USAID.

Demartoto, A. (2012). Need-Based Street Children Management in Surakarta City of Central Java Province of Indonesia. Surakarta: Canadian Center of Science and Education.

Denzin, N.K., \& Lincoln, Y.S. (2000). Qualitative Research. California: Sage Publications, Inc.

Drever, E., \& Munn, P. (1990). Using Questionnaire in Small-Scale Research: A Teachers' Guide, Edinburgh.

Evans, R., \& Becker, S. (2007). Hidden Young Carers: The Experiences, Needs and Resilience of Children Caring for Parents and Relatives with HIV/AIDS in Tanzania and the UK. Stakeholder Report, School of Sociology and Social Policy University of Nottingham, UK

Ezzy, D. (2002). Qualitative Analysis: Practice and Innovation. London: Rutledge.

Fatternam, D.M. (1998). Ethnography: Step by Step. London: International Educational and Professional Publisher.

Fikru, F. (2011). Experiences of mother beggars: The case in Urael Church and the nearby traffic light in Addis Ababa. A Thesis Submitted to the School of Social Work, Addis Ababa University in Partial Fulfillment of the Requirements for the Degree of Masters in Social Work (MSW).

Fives, A; Kennan, D; Canavan, J; Brady, B., \& Cairns, D. (2010). Study of Young Carers in the Irish Population. Dublin: Government Publications.

Frankfort-Nachmias, C., \& Nachmias, D. (1992). Research Methods in the Social Sciences. London: Edward Arnold.

Holland, J. (2008). Young People and Social Capital: What Can It Do For Us? London: Families \& Social Capital Research Group.

Hubberman, A.M., \& Miles, M.B. (1994). Qualitative Data Analysis. London: Sage Publications.

James, A., \& Pront, A. (1997). Constructing and Reconstructing Childhood. London: Falmer Press.

Katsande, R. (2012). Begging for a Title: An Ethnographic Research Report on Zimbabwean Blind Beggars. Masters Dissertation Report.

Lincoln, Y., \& Guba, E. (1985). Naturalistic Inquiry. New York: Sage Publications.

Malindi, M.J., \& Machenjedze, N. (2012). The Role of School Engagement in Strengthening Resilience among Male Street Children. Vaal: Psychological Society of South Africa.

Ministry of Education and Culture. (1995). Education and Training Policy. Dar es Salaam. Retrieved November 29, 2014, from http://www.tzonline.org/pdf/Educationandtrainingpolicy06.pdf

Namwata, B.M.L., \& Mgabo, M.R. (2014). Consequences of Begging and Future Aspirations of Beggars to Stop Begging Life in Central Tanzania. International Research Journal of Human Resources and Social Sciences.Volume1, Issue-4

Namwata, BM.L, Mgabo, M.R., \& Dimoso, P. (2012). Feelings of Beggars on Begging Life and their Survival Livelihoods in Urban Areas of Central Tanzania. International Journal of Physical and Social Sciences, 2(7)

Namwata, B.M.L., Mgabo, M.R., \& Dimoso, P. (2011). Demographic Dimensions and their Implications on the Incidence of Street Begging in Urban Areas of Central Tanzania: the Case of Dodoma and Singida Municipalities. Global Journal of Human Social Science, 11(4).

Namwata, B.M.L., Mgabo, M.R., \& Dimoso, P. (2010). Dynamics of Street Beggars and Begging Life in Urban Areas of Central Zone Tanzania: The Case of Dodoma and Singida Municipalities. The Draft Report Submitted to Research on Poverty Alleviation (REPOA), Dar es Salaam.

Patton, M.Q. (2002). Qualitative Research and Evaluation Methods (3rd Ed.). Thousand Oaks, CA: Sage. 
Pellegrini, A. D. (1998). Observational Methods in Early Childhood Educational Research. In D. Ezzy, Qualitative Analysis: Practice and Innovation. London: Rutledge.

Robson, E., Ansell, N., Huber, U., Gould, W., \& Van Blerk, L. (2006). Young Caregivers in the Context of the HIV/ AIDS Pandemic in Sub- Saharan Africa. Population, Space and Place, 12, 93-111.

Room, G. (1990). Observatory on national policies to combat social exclusion. Synthesis Report. University of Bath.

Rubagumya, C.M. (1991). Language promotion for educational purposes: The example of Tanzania. International Review of Education, 37, 67-85.

Ryan, L. (2007). Social Networks, Social Support, and Social Capital: The Experiences of Recent Polish Migrants in London. London: Middlesex University.

Samoff, J. (1987). School Expansion in Tanzania: Private Initiatives and Public Policy. Comparative Education Review, $31,333-360$.

Sayibu, W. (2013). In Search of Survival? Exploring the Experiences of Children in Child Adult Partnerships for Begging in Tamale, Ghana. Research paper in partial fulfillment of the requirements for obtaining the degree of Master of Arts in Development Studies. The Hague: International Institute of Social Studies.

Save the Children. (2011). Regional Report on Child Begging: Prevalence, Prevention and Suppression of Child Begging' South East Asia: Save the Children.

Seni, A.J. (2016). Access to Basic Education by Young Carers of Visually Impaired Adult Beggars in Tanzania: A Critical Engagement with Policies. International Journal of Education and Research, 4 (12).

Seni, A.J. (2016). The Experiences and Perceptions Encountered by Young Carers of Visually Impaired Adult Beggars in Tanzania: Implications for Access to Basic Education. European Journal of Education Studies 2(1).

Seni, A.J. (2015). Young Carers of Visually Impaired Adult Beggars in Dodoma Municipality, Tanzania: Access to Basic Education. Unpublished PhD Thesis Dodoma: University of Dodoma.

Seni, A.J. (2013). Community Support in Education: Lessons from Shinyanga, Tanzania, Herstellung: LAP Lambert Academic Publishing.

Skovdal, M. (2009). Young Carers in Western Kenya: Collective Struggles and Coping Strategies. London: London School of Economics and Political Science. Social Work, Oxford: Blackwell, p.378.

Suda, C. (1997). Street Children in Nairobi and the African Cultural Ideology of Kin-Based Support System: Change and Challenge. Nairobi: John Wiley \& Sons, Ltd.

UNESCO. (2014). Teaching and Learning: Achieving Quality for All. Place de Fontenoy: UNESCO Publishing.

United Republic of Tanzania. (2000). The Tanzania Development Vision 2025. Dar es Salaam: Planning Commission.

United Republic of Tanzania. (2011). The Tanzania Country Report on the Millenium Development Goals 2010. Dar es Salaam: Planning Commission.

United Republic of Tanzania. (1996). Child Development Policy, 1996, Dar es Salaam: MCDWAC.

United Republic of Tanzania. (2009). The Law of the Child Act, 2009, Dar es Salaam: MCDWAC

Ward, C. L., \& Seager, J. R. (2010). South African Street Children: A survey and Recommendations for Services. Cape Town: Development Bank of Southern Africa. 